Old Dominion University

ODU Digital Commons

Psychology Faculty Publications

Psychology

2005

\title{
The Influence of Sociocultural Factors on Body Image: Searching for Constructs
}

Thomas F. Cash

Old Dominion University

Follow this and additional works at: https://digitalcommons.odu.edu/psychology_fac_pubs

Part of the Clinical Psychology Commons

\section{Repository Citation}

Cash, Thomas F., "The Influence of Sociocultural Factors on Body Image: Searching for Constructs" (2005). Psychology Faculty Publications. 79.

https://digitalcommons.odu.edu/psychology_fac_pubs/79

\section{Original Publication Citation}

Cash, T. F. (2005). The influence of sociocultural factors on body image: Searching for constructs. Clinical Psychology: Science and Practice, 12(4), 438-442. doi:10.1093/clipsy/bpi055

This Article is brought to you for free and open access by the Psychology at ODU Digital Commons. It has been accepted for inclusion in Psychology Faculty Publications by an authorized administrator of ODU Digital Commons. For more information, please contact digitalcommons@odu.edu. 


\section{The Influence of Sociocultural Factors on Body Image: Searching for Constructs}

Thomas F. Cash, Old Dominion University

Body image is a multidimensional construct that has received increasing scientific study over the past few decades. Considerable research has examined the determinants of body image development and functioning and their implications for other aspects of psychosocial wellbeing, especially eating pathology among girls and young women. Cafri, Yamamiya, Brannick, and Thompson (this issue) reported the results of a meta-analysis of how selected, self-reported sociocultural influence variables correlate with the basic dimension of body image evaluation. Their work raises and reinforces important questions about the definition and measurement of sociocultural influence constructs.

Key words: body image, eating pathology, sociocultural, internalization, media, body dissatisfaction, eating disorder. [Clin Psychol Sci Prac 12: 438-442, 2005]

B ody image scholarship has a long and fascinating history (Fisher, 1986, 1990), with strikingly rapid growth over the past two decades (Pruzinsky \& Cash, 2002). Several extensive books devoted to the topic have been published (e.g., Cash \& Pruzinsky, 1990, 2002; Grogan, 1999; Thompson, 1996; Thompson, Heinberg, Altabe, \& Tantleff-Dunn, 1999; Thompson \& Smolak, 2001). In 2004, a peer-reviewed journal commencedBody Image: An International Journal of Research. Certainly, one driving force behind the escalation of body image scholarship is the ardent clinical and scientific interest in eating disorders among girls and young women (Cash, 2004; Striegel-Moore \& Smolak, 2001). The meta-analysis by Cafri, Yamamiya, Brannick, and Thompson (this issue) joins several other extant metaanalyses (e.g., Cash \& Deagle, 1997; Groesz, Levine, \&

Address correspondence to Thomas F. Cash, Department of Psychology, Old Dominion University, Norfolk, VA 23529. E-mail: tcash@odu.edu.
Murnen, 2002; Morrison, Morrison, \& Sager, 2004; Stice, 2002) as examples of attempts to empirically discern the influential or consequential roles of body image variables in eating pathology and other facets of psychosocial functioning.

From cognitive-behavioral perspectives (Cash, 2002), sociocultural factors are seen as powerful determinants of body image development. Thompson and his colleagues have proposed and evaluated a Tripartite Influence Model (Keery, van den Berg, \& Thompson, 2004; Thompson et al., 1999). This model delineates three primary sources of influence vis-à-vis risk factors for the development of body image problems and eating pathology-peers, parents, and media. For example, various literature reviews have highlighted the influential role of the media in the socialization of persons' physical appearance standards and expectations (Levine \& Harrison, 2004; Tiggemann, 2002). Peer and familial influences have been somewhat less studied (Cash \& Pruzinsky, 2002; Wertheim, Paxton, \& Blaney, 2004).

Cafri and colleagues' meta-analysis asks, do the endorsements of various dimensions of sociocultural influence through female beauty ideals serve as moderators of body image difficulties? The researchers' bottom-line findings indicated that the three sociocultural constructs under study (awareness, perceived pressures, and internalization) are all significantly associated with various measures of body image evaluation. As the authors conveyed in their introduction, however, considerable confusion exists with respect to precisely defining these sociocultural constructs and how they are operationalized by various assessments. The boundaries that distinguish the constructs lack clarity. Does the endorsement of the statement "Women with long legs are more attractive" (from the Ideal Body Internalization Scale-Revised; Stice, Ziemba, Margolis, \& Flick, 1996) reflect a passive awareness of cultural beauty standards or an internalization of those standards? If internalization, is it an acquired social schema (belief about others) or a self-schema (a guide for selfevaluation)? If awareness, it does not seem to reflect the same kind of awareness measured by the item "In our society, fat people are regarded as attractive" (reverse-scored), from an early version of the Sociocultural Attitudes Towards Appearance Questionnaire 
(Thompson et al., 1999). This item clearly makes an attribution to a societal norm.

Because the three studied dimensions in Cafri et al. intercorrelated as expected, we cannot be sure how independent their relationships are to body image. The authors properly recognized this fact. For example, Thompson, van den Berg, Roehrig, Guarda, and Heinberg (2004) found that dimensions of internalization and perceived pressures shared over $50 \%$ of common variance in a sample of 175 female college students. In this two-study investigation, standard regression analysis indicated that only the pressures dimension accounted for unique variance in predicting body image dissatisfaction. Calogero, Davis, and Thompson (2004) reported even greater overlap among 440 eating disordered patients. Their standard regression identified not one of the three dimensions as uniquely accounting for body image dissatisfaction.

The most current assessment of media influences is the Sociocultural Attitudes Towards Appearance Questionnaire-version 3 (SATAQ-3; Thompson et al., 2004). It is noteworthy that the awareness dimension has been discarded from this assessment (unlike its earlier versions) presumably because this measure of the mere recognition of sociocultural appearance norms bears little relationship to body image evaluation (Thompson et al., 1999) or because it lacks factor analytic support (Thompson et al., 2004). Being aware that "appearance matters" in our culture is not the same as a personal internalization of beauty norms or feeling pressure to conform to these expectations. On the other hand, the SATAQ-3 does include what the authors labeled an "information" subscale. Calogaro et al. (2004) defined this dimension as "the acknowledgment that information regarding appearance standards is available from media sources" (p. 194). However, a careful examination of its items reveals that they consistently asked whether the media are an "important source of information" about fashion or "being attractive." Thus, endorsement of these items likely reflects more than passive recognition that the media convey such information but rather that respondents value and actively consult the media for such guidance.

What is needed is a clear conceptual framework that articulates how these various constructs should relate to one another and, ultimately, to evaluative body image- particularly along developmental trajectories. For example, media exposure should guarantee awareness of the norms and trends of cultural appearance standards, and without awareness, an internalization of the media mandates would be less likely (although peers and parents are certainly potent alternative sources of influence). One possible path would be that internalization of cultural standards leads persons to increasingly seek media information for important guidance and feedback, which over time instills the media with even greater power and perceived pressure to conform to the internalized ideals.

It is important to clarify one potentially misleading aspect of Cafri and colleagues' article. In their abstract and elsewhere, they indicated that the focus was on constructs pertaining to the "thin ideal." Although the thin ideal is the current cultural standard for body weight, especially for Caucasian females, most of the "independent measures" in the study made no explicit reference to thinness (especially the various versions of Thompson's SATAQ). In fact, these items focused more broadly on the appearance, beauty, attractiveness of media images. One exception was the Perceived Sociocultural Pressures Scale (Stice, Nemeroff, \& Shaw, 1996), included in the meta-analysis. All of its items refer to an experienced pressure from peers, family, or media to be thin or lose weight. Although the media may often confound thinness and physical attractiveness, girls and women have many physical ideals that go beyond body weight. Thus, it may be worthwhile to distinguish between the pursuit of beauty and the pursuit of thinness in relation to perceived sociocultural influences.

A cognitive-behavioral perspective on body image makes various distinctions concerning the multidimensional body image construct (Cash, 2002). One fundamental distinction is between body image evaluation and body image investment. Evaluative body image was Cafri and colleagues' focal "dependent variable." This construct pertains to satisfaction or dissatisfaction with one's appearance, derived from the congruence or discrepancy of one's physical self-percepts and internalized physical ideals. On the other hand, body image investment refers to the psychological (cognitive and behavioral) importance that individuals place on their physical appearance. Investment entails self-schemas 
regarding one's looks - the extent to which persons' organize and process self-relevant information based on their physical appearance. Cash, Melnyk, and Hrabosky (2004) determined that body image investment comes in two "types." The first is the "motivational salience" of one's appearance, or the extent to which people attend to and place value on appearance self-management to "look their best" or enhance their attractiveness. This facet of body image investment is not necessarily maladaptive but may reflect taking care of or taking pride in one's looks. The second facet of the body image investment construct is the "self-evaluative salience" of one's appearance, which concerns the extent to which persons deem their appearance as being integral to their sense of self or self-worth. This type of body image investment is clearly more dysfunctional, as reflected in its relationships with evaluative body image, eating pathology, and other aspects of psychosocial functioning (Cash, Jakatdar, \& Williams, 2004; Cash, Melnyk, et al., 2004; Cash, Phillips, Santos, \& Hrabosky, 2004; Melnyk, Cash, \& Janda, 2004). I propose that the interrelated SATAQ-3 constructs (importance, internalization, and perceived pressures) are indicative of body image investment. How each dimension relates to motivational versus self-evaluative investment awaits further research, but Cash, Melnyk, et al. (2004) did find that internalization on the SATAQ-3 is more strongly related to dysfunctional (self-evaluative) investment than to motivational investment.

My own research record (e.g., Cash \& Pruzinsky, 2002) confirms that I strongly advocate scientifically studying the roles of sociocultural variables in body image development and body image functioning. However, I am not convinced that the sociocultural constructs have been carefully defined and precisely measured such that they will best serve advancing knowledge in this field. There is still much work to do.

Like much of psychology in general (Seligman \& Csikszentmihalyi, 2000) and body image research in particular (Williams, Cash, \& Santos, 2004), Cafri and colleagues' findings may be interpreted from a pathology-driven perspective. The examined dimensions of sociocultural influence are related to body image dissatisfaction. From a "positive psychology" point of view, one can just as accurately interpret their findings in terms of correlates of body image satisfaction or acceptance. The latter raises the important question of protection rather than risk. Why do girls and women reject sociocultural messages about beauty or regard them as being personally irrelevant? For example, an experiment by Yamamiya, Cash, Melnyk, Posavac, and Posavac (2005) revealed that women who scored low on SATAQ-3 internalization were relatively immune to a body image impact from brief exposure to thin and beautiful media models. Moreover, the experimental provision of "media literacy" information (see Levine \& Harrison, 2004) protected women with high internalization from the adverse effects of exposure to thin and beautiful images.

In our appearance-preoccupied culture, it is easy to understand the absorption of ubiquitous cultural messages about physical attractiveness, especially if one recognizes the bioevolutionary underpinnings of these processes (e.g., Etcoff, 1999). Because mediapromulgated messages are absorbed by other socializing agents, especially parents and peers, they are transmitted and reinforced in everyday social interactions. Perhaps our greatest challenge is to understand persons who are resilient to such pervasive sociocultural forces. Our other formidable challenges in the field of body image research (Cash, 2004; Cash \& Pruzinsky, 2002) are to transcend its gender-biased, Western-culture, eating disorder-driven focus. All people are embodied, and their lives are powerfully shaped by the personal and cultural meanings of their physical appearance.

\section{REFERENCES}

Cafri, G., Yamamiya, Y., Brannick, M., \& Thompson, J. K. (2005). The influence of sociocultural factors on body image: A meta-analysis. Clinical Psychology: Science and Practice, 12, 421-433.

Calogero, R. M., Davis, W. M., \& Thompson, J. K. (2004). The Sociocultural Attitudes Towards Appearance Questionnnaire (SATAQ-3): Reliability and normative comparisons of eating disordered patients. Body Image: An International Journal of Research, 1, 193-198.

Cash, T. F. (2002). Body image: Cognitive behavioral perspectives. In T. F. Cash \& T. Pruzinsky (Eds.), Body image: $A$ handbook of theory, research, and clinical practice (pp. 38-46). New York: Guilford Press.

Cash, T. F. (2004). Body image: Past, present, and future. Body Image: An International Journal of Research, 1, 1-5. 
Cash, T. F., \& Deagle, E. A., III (1997). The nature and extent of body-image disturbances in anorexia nervosa and bulimia nervosa: A meta-analysis. International Journal of Eating Disorders, 22, 107-125.

Cash, T. F., Jakatdar, T. A., \& Williams, E. F. (2004). The Body Image Quality of Life Inventory: Further validation with college men and women. Body Image: An International Journal of Research, 1, 305-316.

Cash, T. F., Melnyk, S. E., \& Hrabosky, J. I. (2004). The assessment of body image investment: An extensive revision of the Appearance Schemas Inventory. International Journal of Eating Disorders, 35, 305-316.

Cash, T. F., Phillips, K. A., Santos, M. T., \& Hrabosky, J. I. (2004). Measuring "negative body image": Validation of the Body Image Disturbance Questionnaire in a nonclinical population. Body Image: An International Journal of Research, 1, 363-372.

Cash, T. F., \& Pruzinsky, T. (Eds.). (1990). Body images: Development, deviance, and change. New York: Guilford Press.

Cash, T. F., \& Pruzinsky, T. (Eds.). (2002). Body image: A handbook of theory, research, and clinical practice. New York: Guilford Press.

Etcoff, N. (1999). Survival of the prettiest: The science of beauty. New York: Doubleday.

Fisher, S. (1986). Development and structure of the body image (Vols. 1-2). Hillsdale, NJ: Erlbaum.

Fisher, S. (1990). The evolution of psychological concepts about the body. In T. F. Cash \& T. Pruzinsky (Eds.), Body images: Development, deviance, and change (pp. 3-20). New York: Guilford Press.

Groesz, L., Levine, M. P., \& Murnen, S. K. (2002). The effect of experimental presentation of thin media images on body satisfaction: A meta-analytic review. International Journal of Eating Disorders, 31, 1-16.

Grogan, S. (1999). Body image: Understanding body dissatisfaction in men, women and children. London: Routledge.

Keery, H., van den Berg, P., \& Thompson, J. K. (2004). An evaluation of the Tripartite Influence Model of body dissatisfaction and eating disturbance with adolescent girls. Body Image: An International Journal of Research, 1, 236-251.

Levine, M. P., \& Harrison, K. (2004) Media's role in the perpetuation and prevention of negative body image and disordered eating. In J. K. Thompson (Ed.), Handbook of eating disorders and obesity (pp. 695-717). Hoboken, NJ: Wiley.

Melnyk, S. E., Cash, T. F., \& Janda, L. H. (2004) Body image ups and downs: Prediction of intra-individual level and variability of women's daily body image experiences. Body Image: An International Journal of Research, 1, 225-235.
Morrison, M. A., Morrison, T. G., \& Sager, C. L. (2004). Does body satisfaction differ between gay men and lesbian women and heterosexual men and women? A metaanalytic review. Body Image: An International Journal of Research, 1, 127-138.

Pruzinsky, T., \& Cash, T. F. (2002) Understanding body images: Historical and contemporary perspectives. In T. F. Cash \& T. Pruzinsky (Eds.), Body image: A handbook of theory, research, and clinical practice (pp. 3-12). New York: Guilford Press.

Seligman, M. E. P., \& Csikszentmihalyi, M. (Eds.). (2000). Positive psychology [Special issue]. American Psychologist, $55(1)$.

Stice, E. (2002). Risk and maintenance factor for eating pathology: A meta-analytic review. Psychological Bulletin, $128,825-848$.

Stice, E., Nemeroff, C., \& Shaw, H. (1996). A test of the dual pathway model of bulimia nervosa: Evidence for restrained-eating and affect regulation mechanisms. Journal of Social and Clinical Psychology, 15, 340-363.

Stice, E., Ziemba, C., Margolis, J., \& Flick, P. (1996). The dual pathway model differentiates bulimics, subclinical bulimics, and controls: Testing the continuity hypothesis. Behavior Therapy, 27, 531-549.

Striegel-Moore, R. H., \& Smolak, L. (2001). Eating disorders: Innovative directions in research and practice. Washington, DC: American Psychological Association.

Thompson, J. K. (Ed.). (1996). Body image, eating disorders, and obesity: An integrative guide for assessment and treatment. Washington, DC: American Psychological Association.

Thompson, J. K., Heinberg, L. J., Altabe, M., \& TantleffDunn, S. (1999). Exacting beauty: Theory, assessment, and treatment of body image disturbance. Washington, DC: American Psychological Association.

Thompson, J. K., \& Smolak, L. (Eds.). (2001). Body image, eating disorders, and obesity in youth: Assessment, prevention, and treatment. Washington, DC: American Psychological Association.

Thompson, J. K., van den Berg, P., Roehrig, M., Guarda, A. S., \& Heinberg, L. S. (2004). The Sociocultural Attitudes Towards Appearance Scale-3 (SATAQ-3): Development and validation. International Journal of Eating Disorders, 35 , 293-304.

Tiggemann, M. (2002). Media influences on body image development. In T. F. Cash \& T. Pruzinsky (Eds.), Body image: $A$ handbook of theory, research, and clinical practice (pp. 91-98). New York: Guilford Press.

Wertheim, E. H., Paxton, S., J., \& Blaney, S. (2004). Risk factors for the development of body image disturbances. 
In J. K. Thompson (Ed.), Handbook of eating disorders and obesity (pp. 463-494). Hoboken, NJ: Wiley.

Williams, E. F., Cash, T. F., \& Santos, M. T. (2004, November). Positive and negative body image: Precursors, correlates, and consequences. Poster presented at the annual meeting of the Association for Advancement of Behavior Therapy, New Orleans, LA.
Yamamiya, Y., Cash, T. F., Melnyk, S. E., Posavac, H. D., \& Posavac, S. S. (2005). Women's exposure to thin-andbeautiful media images: Body image effects of media-ideal internalization and impact-reduction interventions. Body Image: An International Journal of Research, 2, 74-80.

Received June 2, 2005; accepted July 28, 2005. 